\title{
Investigating of the Relationship between Job Satisfaction and Organizational Commitment Case Study; Professors and Administrative Staff of the Logar University
}

\section{Assistant Professor Muhammad Tahir Khaplwak, Associate Professor Abdul Azim Mommand and Associate Professor Wahidullah Abdulrahimzai}

Assistant Professor of Psychology and Educational Sciences at Logar University - Afghanistan Associate Professor of Psychology and Educational Sciences at Kabul University - Afghanistan Associate Professor of Education Faculty at Logar University - Afghanistan

\begin{abstract}
Job satisfaction and organizational commitment that play a very important role in the growth and survival of organizations and reduce delays and layoffs of employees and increase the level of efficiency and effectiveness in organizations. The study, entitled "Investigating the Relationship between Job Satisfaction and Organizational Commitment from the Perspective of Professors and Administrative Staff of the Logar University" is a descriptive-correlational study. Its main purpose was to study the relationship between job satisfaction and organizational commitment. The statistical population is the professors and staff of the University of Logar University. Due to the small number of professors and staff of this institution, all of them (30) have been included in the research. In this study, the required information was collected by two questionnaires of job satisfaction and organizational commitment and was analyzed using SPSS24 and EXCEL software and its descriptive and inferential results are described in the tables, which in the descriptive method describes the variables of satisfaction. Job (nature of work, co-workers, growth opportunities and payments) and organizational commitment variables (emotional commitment, continuous commitment and normative commitment) and in inferential analysis by correlation test or Pearson correlation to test hypotheses and analyze the relationship between Job satisfaction $\mathbf{J}$ and organizational commitment are addressed. The results of the research show that the majority of the employees of this institution are satisfied with their work; but they are not satisfied with the behavior and attitude of the supervisors. On the contrary, the majority of the employees of this institution read the behavior of their colleagues as friendly and satisfied. The majority of the employees of this organization have said that there is no suitable opportunity for growth and promotion. The majorities of the employees of this institution are interested in this organization and consider the problems of the organization as their problems; but they do not see the current organization as suitable for securing their future, and they will leave the organization if they are offered a better job elsewhere. The results showed that the majority of the faculty and staff of this organization are below the level of job satisfaction (supervisors, growth opportunities and payments) and are below the level of continuous commitment.

Regarding the hypotheses, the research showed that there is no relationship between the nature of work and emotional commitment. There is a significant relationship between the behavior of supervisors and normative commitment. There is no significant relationship between employee behavior and normative commitment. There is a significant and positive relationship between growth opportunities and pay and continuous commitment. There is a positive and significant relationship between job satisfaction and organizational commitment of the professors and staff of the Logar University.
\end{abstract}


Key Words: Job satisfaction, organizational commitment and Logar University.

\section{Introduction}

In order to survive, organizations must focus more on efficiency and effectiveness. One of the most important tasks of any organization is to achieve its goals. Manpower as an important and prominent factor in achieving the goals of the organization has a significant role. The presence of human resources in the organization is accompanied by an increase in the level of performance and a decrease in the rate of absenteeism, delays and leaving the service of employees, and makes the face of the organization appropriate in society and provides the basis for growth and development of the organization. Conversely, human resources with a low sense of loyalty and organizational commitment and willing to leave the organization, not only does not move towards achieving organizational goals, but also is effective in creating a culture of disregard for the issues and problems of the organization among other colleagues.

A competent manager uses the human and material resources of the organization to achieve the goals, removes the organization from a state of confusion and ambiguity. Increasing the efficiency of the manager requires the adaptation of internal performance to the functions, technologies, needs of employees and the external environment of the organization (Rezaian, 2003). Efficient use of human resources, which will increase productivity, is directly related to increasing the commitment of the organization to the desired level (Khaki, 2005, 41). Lack of attention to human resource management in organizations and departments, as well as the use of non-scientific methods in human development, affects the emotional and psychological dependence of the individual on his organization and causes a lack of sense of responsibility, loyalty and commitment among employees. .

\section{Problem Statement}

National development of a country is not possible except with the help of efficient human resources. The human resources of any organization are considered as the main and most enduring capital of that organization. Therefore, it is necessary to be aware of their publications in order to implement the organization's programs. Organizations invest large sums of money in their human resources each year to reduce costs, increase quality, increase customer satisfaction, and improve operations. The Logar University, as a public educational institution, as well as the size of organizations, seeks to achieve its maximum efficiency and effectiveness (achievement of goals) by growing and strengthening its human resources. Efficiency concerns have become an issue for the management of this institution, which may cause human resources problems in this scientific institution if it is not solved and the efficiency of employee's decreases. The Logar University is looking to increase its efficiency. Recent developments due to the dissatisfaction of faculty and staff and the recruitment of new staff in recent months show that adapting to this new situation has resulted in the time and energy of most staff. They do not have much commitment to their duty and seek to find duties in other institutions. At the same time, it is very difficult to find qualified and qualified people and attract them as members of the scientific staff of a long-term process and work. The new teacher and staff member should make every effort to fill the vacancy caused by the previous teacher and staff member leaving the job, and on the other hand, other professors and staff members should share their related duties and responsibilities with the new teacher and staff member and make arrangements. Do the necessary to inform the new teacher and staff about the work process. With this in mind, the Logar University seeks to reduce the quality of work and strengthen the organization by retaining existing staff and preventing an increase in the tendency to leave, an increase in leaving, more absenteeism and poor performance. Informal, this is stronger than the formal organization and against the formal organization, by strengthening a positive and emotional attitude towards the job of individuals (job satisfaction) to strengthen the commitment of the organization and ultimately increase efficiency and achieve organizational goals. 
In most public and private organizations in Afghanistan, unfortunately, ignoring the expectations, expectations, needs and general attitudes of individuals has led to the neglect of their satisfaction in the job they are playing, and the job commitment that gives a person the strength to Move towards the realization of the goals of the organization, it is considered as a hidden dimension of the organizations and no serious attention has been paid to them. This has led to a lack of motivation and creativity, perseverance and positive attitude of people towards the organization, leading to dissatisfaction that led to leaving the organization and eventually the loss of manpower in organizations. Therefore, the research seeks to investigate the relationship between job satisfaction and commitment of the employees of this educational institution.

\section{Importance and necessity of research}

The key to the success of organizations is their human resources, and the key to the success of the organization's human resources in their performance and function, and their commitment to the organization in which they work. Manpower is the most important asset of organizations and the more commitment individuals have to the organization, the higher the desired quality and the greater the probability of success, survival and promotion of the organization. The presence of human resources committed to the organization in any organization, while reducing absenteeism, latency and relocation, will significantly increase the performance of the organization, the morale of employees to better manifest the lofty goals of the organization and also achieve individual goals. The absence of committed employees or employees with low level of commitment has negative consequences for the individual and the organization. These results include leaving the service, absenteeism, tardiness, reluctance to stay in the organization, reduced employee confidence, and reduced effectiveness. The presence of committed manpower makes the face of the organization important in the community and provides the basis for the growth and development of the organization. Therefore, having employees who are committed and loyal to the organization is one of the main and basic needs of the organization. Considering the role that job satisfaction has on the organizational commitment of employees in organizations, it can be seen that job satisfaction and organizational commitment as the main elements in the principle of continuity and survival of the organization has a special place.

\section{Research objectives \\ Main purpose:}

To investigate the relationship between job satisfaction and organizational commitment of professors and administrative staff of the Logar University.

\section{Sub-objectives}

1. Finding the relationship between the nature of work and the emotional commitment of the professors and administrative staff of the Logar University.

2. Finding the relationship between the behavior of managers and colleagues and the normative commitment of professors and administrative staff of the Logar University.

3. Finding the relationship between growth opportunities and payments and the ongoing commitment of the professors and staff of the Logar University.

\section{Hypotheses}

\section{Main Hypothesis:}

There seems to be a relationship between job satisfaction and organizational commitment of professors and administrative staff of the Logar University.

\section{Sub-hypotheses}


1. There seems to be a relationship between the nature of the work and the emotional commitment of the professors and staff of the Logar University.

2. There seems to be a relationship between the behavior of managers and colleagues and the normative commitment of professors and administrative staff of the Logar University.

3. There seems to be a relationship between growth opportunities and payments and the continued commitment of the professors and staff of the Logar University.

\section{Define research variables}

Job satisfaction: Satisfaction is an ideal state of psychological process. Job satisfaction is a multidimensional concept that includes the sum of employees' good and bad feelings about their jobs (Bernal, Castel, Navarro, $\&$ Torres, 200).

Commitment: Commitment literally means to use a job, to undertake, to have nine, to make a covenant in the future (Maxwell, 2008).

Organizational commitment: Organizational commitment is an approach about employee loyalty to the organization and a continuous process that, through the participation of individuals in organizational decisions, pays attention to the people of the organization and the success and welfare of the organization (Moghimi, 2006). Organizational commitment can have many positive consequences. Employees who have high commitment, have more order in their work, stay longer in the organization and work more (Morehead and Orfin, 2001)

\section{Theoretical Foundations}

\section{Job definition}

Work and occupation is a physical or intellectual activity in the field of production and service. Work is an activity that is asked of someone and in return, he is paid. In another definition, a job is a group of similar positions in an institution, office or workplace that people with special qualifications can achieve these positions and perform the assigned tasks (Shafiabadi, 2007). In short, a job is a job that a person does and through which he or she does both work and earn a living.

\section{Job Satisfaction}

Job satisfaction is one of the most important factors in increasing efficiency and creating a positive attitude in a person towards his work. Employees who are satisfied with their job are those who act collaboratively and in groups and have a high level of motivation (Robbins and Jaj, 2012). According to Hopack, job satisfaction is a multidimensional concept and is related to psychological, physical and social factors. Not only one factor causes job satisfaction, but the combination of a set of factors causes the employee to feel satisfied with his job at a certain moment of time and to say that he is satisfied with his job and enjoys it (Safiri. 133). Job satisfaction increases performance, and the more job satisfaction a person has in the workplace, the greater the innovation and creativity at work, the lower the employee turnover rate, and the higher the organization's production and services. On the contrary, dissatisfied people leave the organization and resign more often. There are many factors that affect job satisfaction; in short, the following factors can be summarized: social factors, work ethic, work environment, job satisfaction, satisfaction with superiors, satisfaction with colleagues, satisfaction with promotion and satisfaction with salary (Kouhestani, and Shajahifar, 2001).

\section{Organizational Commitment}

Organizational commitment is a kind of spiritual and intellectual relationship and devotion to the goals and missions of the organization. Organizational commitment is a kind of inner attitude and feeling towards the organization that affects performance, loyalty and judgments towards the organization. Commitment can 
have many positive consequences: Employees who are committed and have more order in their work, stay longer in organizations and work harder. Therefore, managers should be able to increase employee commitment in various ways (Majidi, 1998). Organizational commitment is the degree to which the employee is dependent on a particular organization and the extent to which the organization helps to achieve individual goals (Robbins and Jaj, 1 r $^{*}$ ). Organizational commitment is a mentality and a state of mind that indicates the desire, need and obligation to continue in an organization. In the meantime, desire means a person's heartfelt desire to continue serving in the organization, and need means that the person, especially the investments he has made in the organization, is forced to continue serving in it. Also, obligation is the religion, responsibility and duty that a person has towards the organization and feels obligated to stay in it.

Employee commitment is a strong and effective force in the success of the organization. Employees with commitment are more disciplined, stay longer in the organization, and work harder. Managers must maintain the commitment and commitment of employees to the organization and for this they must be able to increase employee commitment and commitment by using employee participation in decision making and providing them with an acceptable level of job security (Erifen and Morehead, 2010).

A study by McMuriver on the success of Japan has revealed that the Japanese are successful because they have created strong organizational cultures in their organizations. This stems from the existence of common values between management and employees in a mutual way and advised organizations to trust people and treat them like adults and involve them in decisions (Bakhshi, 2016).

\section{Types of organizational commitment}

1. Commitment to the customer or client;

2. Commitment to the organization;

3. Commitment to self;

4. Commitment to individuals and groups; and

5. Commitment to work (Hershey and Blanchard, 1373).

Dimensions of organizational commitment

Organizational commitment has three dimensions or three aspects, which are: emotional commitment, normative commitment and continuous commitment.

\section{Emotional commitment}

Emotional commitment is the most important element of organizational commitment and is defined as an individual's attachment to the organization. In this case, the person stays in the organization because he has a positive feeling and attitude towards its mission, values and goals and wants to fulfill the goals of that organization. Employees who have a higher emotional commitment, adhere to their values more and find themselves committed to achieving the goals of the organization (Baharifar and Javaheri Kamel, 2010)

\section{Normative commitment}

Normative commitment is defined as a type of commitment and commitment that leads employees to feel that they stay with the organization. The person stays in the organization because of norms and ethics. One does not leave the organization because others judge how to leave the organization. This type of commitment is due to the fact that Kamand feels that the organization has treated him well and therefore, he is indebted to the organization (Baharifar and Javaheri Kamel, 2010).

\section{Continuous commitment}

Continuous commitment to the organization is due to awareness of the costs of leaving the organization. That is, a person stays in the organization because it results in a cost-benefit analysis, which he needs to stay 
in. Many times he stays because he does not want to look for a new job. This commitment and staying in the organization is a continuous commitment (continuous, mandatory and retention); That is, he stays in the organization because going to another organization is costly (Gholipour and Diran, 2007). Employees in the organization remember that they think the cost of leaving the organization is probably too high.

\section{Literature Review}

Ashrafi (1995) in a study entitled (Factors affecting the organizational commitment of managers and employees of East Alborz Coal Company) concluded that there is a direct relationship between job satisfaction and the level of organizational commitment of managers and employees. Vahidian Rezazadeh (2002) in studying the relationship between job satisfaction and organizational commitment has shown that factors such as job satisfaction, satisfaction of supervisor, satisfaction with colleagues, the possibility of job promotion and salaries and benefits, have affected the level of organizational commitment of employees. Azizi (2011) conducted a study on the relationship between job satisfaction and organizational commitment. The results indicate that there is a direct and significant relationship between employee job satisfaction and organizational commitment. Bazvand, Kashif and Ismaili ( 2013) In a study conducted on 50 employees of the General Department of Physical Education in Lorestan Province of Iran, they concluded that there is a direct and significant relationship between organizational commitment and job satisfaction. Alnjaz (1996) A study on the relationship between satisfaction Jobs and Organizational Commitment among UAE Employees and found that there is a significant relationship between managers and co-workers, salaries and job privileges with organizational commitment. Several organizations in the UAE have found that there is a positive and meaningful relationship between work ethic and organizational commitment. Findler, Wind, \& Barak (2007) Community, organizational culture, employee well-being, job satisfaction and organizational commitment. Do the reviews. The results showed that with increasing the culture and income of employees, job satisfaction and as a result their organizational commitment increases and there is also a relationship between job satisfaction and organizational commitment. Wood et al. (2007) in a study entitled (Study of the relationship between job satisfaction and organizational commitment components in American suppliers), the results showed that there is a relationship between job satisfaction and organizational commitment.

In the article by Idrisi and Raisi Ardali entitled "Comparison of job satisfaction and efficiency of staff and non-faculty managers in Isfahan University of Technology", the variables affecting the efficiency of university staff were examined. Studies have shown that job satisfaction, rewards external and internal, job characteristics, up and down communication, leadership satisfaction, promotion status, trust in supervisors, organizational life, motivation for employees to learn and understand the values of the organization are associated with organizational commitment (Boulon, 1977).

In a study of 1,041 faculty members at the University Of Australia, Winter and Saros found that the variables of role ambiguity, role burden, role conflict, and administrative hierarchy correlated negatively with organizational commitment. At the same time, variables related to job characteristics, supportive leadership style, and faculty participation rate correlate positively and meaningfully with organizational commitment.

In 1995, Herzberg, in a study of more than 200 engineers and accountants in meeting needs, motivation, and job satisfaction, asked them to consider their issues, feelings, and perceptions over the years of service. What do they want from their job?

The overall conclusion of these studies was as follows:

1. Satisfaction of environmental-health needs only prevents people from being dissatisfied; but it does not necessarily cause their motivation and efficiency. 
2. In order for people to be aroused, their educational needs must be met. As a result, when people feel satisfied from within, their efficiency and success increase.

3. In order for a person not to be dissatisfied and at the same time to work with high morale and sufficient motivation to achieve great success and efficiency, it is necessary to satisfy both his health and environmental factors and his motivating factors. Also, Robert's 1987 study shows that job-satisfied teachers have a more positive attitude toward students and the teaching profession.

A summary of the research shows that the relationship between job satisfaction and organizational commitment and its dimensions has been confirmed in many researches that have been done on different jobs.

\section{Research Method}

This research is applied in terms of purpose and descriptive-correlative in terms of method that has examined the relationship between independent variable (job satisfaction) and dependent variable (organizational commitment) of professors and administrative staff of the Logar University. In this type of research, if the relationship between two or more variables is received. This relationship should be interpreted in terms of intensity and direction by a correlation coefficient between negative one and positive one. The correlation or relationship between two variables can show a positive relationship (zero to positive 1), which means that when one variable increases, the other variable also increases, and vice versa, the correlation coefficient between (zero to negative 1) Shows a negative relationship. That is, a correlation coefficient close to one (positive or negative) indicates a direct relationship, while a zero correlation coefficient indicates the absence of a relationship, and a negative correlation coefficient indicates an inverse relationship.

In this research, information has been collected using a standard questionnaire and it has been described without any change in the description and relationship of variables. The present study was conducted at the Logar University-Afghanistan State University. Its statistical population is the university and its administrative staff is the Logar state University. Since the university is a newly established university, all 30 professors and administrative staff are included in the study. The collected data were analyzed using SPSS21 and EXCEL software and the results are shown and described in the tables.

\section{Descriptive analysis}

In descriptive analysis, citing the figures obtained, it can be seen that in terms of the nature of work, the majority of respondents found that they were satisfied with work; but their jobs also require creativity and initiative. Regarding the behavior of supervisors, the figures show that most of the professors and employees of this institution are not satisfied with the behavior and attitude of their supervisors. Regarding the behavior of co-workers, based on the obtained figures, it can be seen that the majority of co-workers do not feel responsible at work. The majority of respondents found that co-workers treat each other friendly and cordial. Regarding growth and promotion opportunities, the majority of respondents said that they work in an organization that does not have growth and promotion opportunities and if so, which is very limited. Also, it is said that they work in an organization where promotion is not based on ability and is not implemented legally and regularly. Regarding payments, the majority of respondents found that their income was low, their salaries were not adequate, they could not solve their living problems with their livelihood, and their livelihoods barely covered their living expenses. Regarding the commitment, the figures, shows that the majority of the respondents have found that they are interested in this organization and consider the problems of the organization as their problems. Also, the majority say that they do not consider the current organization suitable for them to guarantee their future, and they leave the organization if a better job is offered to them elsewhere. 


\section{Inferential analysis}

Satisfaction with the organization and the organization of the term Pearson Correlation is known as the mediator. What state do you live in?

First Sub-Hypothesis: There seems to be a relationship between the nature of work and the emotional commitment of the professors and staff of the Logar state University.

Correlation between the nature of work and emotional commitment

\begin{tabular}{|c|c|c|c|}
\hline \multirow{2}{*}{ Nature of work } & Pearson Correlation & 1 & $\begin{array}{c}\text { Emotional } \\
\text { commitment }\end{array}$ \\
\cline { 2 - 4 } & Sig. (2-tailed) & & .035 \\
\cline { 2 - 4 } & $\mathrm{N}$ & 26 & .870 \\
\hline \multirow{2}{*}{$\begin{array}{c}\text { Emotional } \\
\text { commitment }\end{array}$} & Pearson Correlation & .035 & 26 \\
\cline { 2 - 4 } & Sig. (2-tailed) & .870 & 26 \\
\cline { 2 - 4 } & $\mathrm{N}$ & 26 & 26 \\
\hline
\end{tabular}

Table (1): The relationship between the nature of work and emotional commitment

Table 1 shows that there is no relationship between the nature of work component of the job satisfaction variable and the emotional commitment component of the organizational commitment variable. Because the correlation coefficient of these two components (0.035) and the price (P-Value) or its significance level is also (0.870). Therefore, we conclude that the first sub-hypothesis of the research is rejected.

Second sub-hypothesis: There seems to be a relationship between the behavior of supervisors and coworkers and the normative commitment of employees.

The Relationship between Supervisor Behavior and Value Commitment (Normative)

\begin{tabular}{|c|c|c|c|}
\hline \multirow{3}{*}{ Supervisors } & & Supervisors & Value commitment \\
\cline { 2 - 4 } & $\begin{array}{c}\text { Pearson } \\
\text { Correlation }\end{array}$ & 1 & $.813^{* *}$ \\
\cline { 2 - 4 } & Sig. (2-tailed) & & .000 \\
\cline { 2 - 4 } & $\mathrm{N}$ & 26 & 26 \\
\hline Value commitment & $\begin{array}{c}\text { Pearson } \\
\text { Correlation }\end{array}$ & $.813^{* *}$ & 1 \\
\cline { 2 - 4 } & Sig. (2-tailed) & .000 & 26 \\
\cline { 2 - 4 } & $\mathrm{N}$ & 26 & \\
\hline
\end{tabular}

Table (2): The relationship between guardian behavior and value commitment (normative)

Table 2 shows that there is a positive and significant relationship between the component of supervisors from the variable of job satisfaction and the component of normative commitment from the variable of organizational commitment. So that the correlation coefficient of these two components is $(0.813 * *)$ and its price or significance level is (.0000). So, the second hypothesis is also rejected.

Correlation between peer behavior and normative commitment

\begin{tabular}{|c|c|c|c|}
\hline \multirow{3}{*}{ Partners } & & Partners & Normative \\
\hline \multirow{7}{*}{} & $\begin{array}{c}\text { Pearson } \\
\text { Correlation }\end{array}$ & 1 & -.019 \\
\cline { 2 - 4 } & Sig. (2-tailed) & & .929 \\
\cline { 2 - 4 } & $\mathrm{N}$ & 25 & 25 \\
\hline
\end{tabular}




\begin{tabular}{|c|c|c|c|}
\hline Normative & $\begin{array}{c}\text { Pearson } \\
\text { Correlation }\end{array}$ & -.019 & 1 \\
\cline { 2 - 4 } & Sig. (2-tailed) & .929 & 26 \\
\cline { 2 - 4 } & $\mathrm{N}$ & 25 & \\
\hline
\end{tabular}

Table (3): The relationship between peer behavior and value commitment

Table 3 shows that there is no relationship between the component of colleagues from the variable of job satisfaction and the component of value commitment from the variable of organizational commitment. So that the correlation coefficient of these two components is $(-0.199)$ and the price) or its significance level is (.9290). So the second hypothesis is also rejected.

Third sub-hypothesis: There seems to be a relationship between growth opportunities and payments with continued commitment.

Correlation between opportunities for growth and continuous commitment

\begin{tabular}{|c|c|c|c|}
\hline & & $\begin{array}{c}\text { Growth } \\
\text { opportunities }\end{array}$ & $\begin{array}{l}\text { Continuous } \\
\text { commitment }\end{array}$ \\
\hline \multirow[t]{3}{*}{ Growth opportunities } & $\begin{array}{c}\text { Pearson } \\
\text { Correlation }\end{array}$ & 1 & $.848^{* * *}$ \\
\hline & Sig. (2-tailed) & & .000 \\
\hline & $\mathrm{N}$ & 26 & 26 \\
\hline \multirow[t]{3}{*}{$\begin{array}{l}\text { Continuous } \\
\text { commitment }\end{array}$} & $\begin{array}{c}\text { Pearson } \\
\text { Correlation }\end{array}$ & $.848^{* * *}$ & 1 \\
\hline & Sig. (2-tailed) & .000 & \\
\hline & $\mathrm{N}$ & 26 & 26 \\
\hline
\end{tabular}

Table (4): Relationship between growth opportunities and continuous commitment

Table 4 shows that there is a positive and significant relationship between the component of growth opportunities from the variable of job satisfaction and the component of commitment inherent from the variable of organizational commitment. So that the correlation coefficient between these two components is $(0.848 * *)$ and its price or significance level is (.0000). So the third hypothesis is confirmed.

\section{Correlation between payments and ongoing commitment}

\begin{tabular}{|c|c|c|c|}
\hline & & Payments & $\begin{array}{l}\text { Continuous } \\
\text { commitment }\end{array}$ \\
\hline \multirow[t]{3}{*}{ Payment } & $\begin{array}{c}\text { Pearson } \\
\text { Correlation }\end{array}$ & $.506^{* *}$ & 1 \\
\hline & Sig. (2-tailed) & .010 & \\
\hline & $\mathrm{N}$ & 26 & 26 \\
\hline \multirow[t]{3}{*}{$\begin{array}{l}\text { Continuous } \\
\text { commitment }\end{array}$} & $\begin{array}{c}\text { Pearson } \\
\text { Correlation }\end{array}$ & 1 & $.506^{* * *}$ \\
\hline & Sig. (2-tailed) & & .010 \\
\hline & $\mathrm{N}$ & 26 & 26 \\
\hline
\end{tabular}

Table (5): Relationship between payments and ongoing commitment

Table 5 shows that there is a weak relationship between the component of payments from the variable of job satisfaction and the component of continuous commitment from the variable of organizational commitment. So that the correlation coefficient of these two components is $(.506 * * 0)$ and its price or significance level is (0.010). So the third hypothesis is confirmed. 
Main research hypothesis: There seems to be a relationship between job satisfaction and organizational commitment of professors and administrative staff of the Logar state University.

Correlation between job satisfaction and organizational commitment

\begin{tabular}{|c|c|c|c|}
\hline \multirow{3}{*}{ Job Satisfaction } & $\begin{array}{c}\text { Pearson } \\
\text { Correlation }\end{array}$ & 1 & $\begin{array}{c}\text { Organizational } \\
\text { Commitment }\end{array}$ \\
\cline { 2 - 4 } & Sig. (2-tailed) & $\mathrm{N}$ & $.661^{* *}$ \\
\cline { 2 - 4 } & $\mathrm{N}$ & 26 & .000 \\
\hline \multirow{2}{*}{$\begin{array}{c}\text { Organizational } \\
\text { Commitment }\end{array}$} & $\begin{array}{c}\text { Pearson } \\
\text { Correlation }\end{array}$ & $.661^{* *}$ & 26 \\
\cline { 2 - 4 } & Sig. (2-tailed) & .000 & 1 \\
\cline { 2 - 4 } & $\mathrm{N}$ & 26 & 26 \\
\hline
\end{tabular}

Table (6): The relationship between job satisfaction and organizational commitment

Table 6 shows that among the job satisfaction variable, there is a good and significant organizational commitment variable. So that the correlation coefficient of these two variables is $(0.661 * *)$ and its price or significance level is (.0000). So the main research is confirmed.

According to the results of inferential analysis of the research, it can be seen that the first and second hypotheses of the research are rejected and the third hypothesis of the research is confirmed and the main hypothesis of the research is also confirmed.

\section{Discussion}

In the results of previous research, a very important and serious issue that has become more apparent is that there is a significant relationship between job satisfaction and organizational commitment. For example, in a study (1995) entitled (Factors affecting the organizational commitment of managers and employees of East Alborz Coal Company) concluded that there is a direct relationship between job satisfaction and the level of organizational commitment of managers and employees. Our research is similar to this research.

Vahidian Rezazadeh (2002) in (Study of the relationship between job satisfaction and organizational commitment) has shown that factors such as job satisfaction, satisfaction of supervisor, satisfaction with colleagues, the possibility of job promotion and salaries and benefits, have affected the level of organizational commitment of employees . The present study also shows. Azizi (2011) conducted a study on the relationship between job satisfaction and organizational commitment. The results indicate that there is a direct and significant relationship between employee job satisfaction and organizational commitment. Bazvand, Kashif and Ismaili ( 2013) In a study conducted on 50 employees of the General Department of Physical Education in Lorestan Province of Iran, they concluded that there is a direct and significant relationship between organizational commitment and job satisfaction. Alnjaz (1996) A study on the relationship between satisfaction Jobs and Organizational Commitment among UAE Employees and found that there is a significant relationship between managers and co-workers, salaries and job privileges with organizational commitment. Several organizations in the UAE have found that there is a positive and meaningful relationship between work ethic and organizational commitment. Findler, Wind, \& Barak (2007) Community, organizational culture, employee well-being, job satisfaction and organizational commitment, do the reviews. The results showed that with increasing the culture and income of employees, job satisfaction and as a result their organizational commitment increases and there is also a relationship between job satisfaction and organizational commitment. Wood et al. (2007) in a study entitled (Study of the 
relationship between job satisfaction and organizational commitment components in American suppliers), the results showed that there is a relationship between job satisfaction and organizational commitment.

In the article by Idrisi and Raisi Ardali entitled "Comparison of job satisfaction and efficiency of staff and non-faculty managers in Isfahan University of Technology", the variables affecting the efficiency of university staff were examined. Studies have shown that job satisfaction, rewards External and internal, job characteristics, up and down communication, leadership satisfaction, promotion status, trust in supervisors, organizational life, motivation for employees to learn and understand the values of the organization are associated with organizational commitment (Boulon, 1977).

In a study of 1,041 faculty members at the University of Australia, Winter and Saros found that the variables of role ambiguity, role burden, role conflict, and administrative hierarchy correlated negatively with organizational commitment. At the same time, variables related to job characteristics, supportive leadership style, and faculty participation rate correlate positively and meaningfully with organizational commitment.

In 1995, Herzberg, in a study of more than 200 engineers and accountants in meeting needs, motivation, and job satisfaction, asked them to consider their issues, feelings, and perceptions over the years of service. What do they want from their job?

\section{The overall conclusion of these studies was as follows:}

1. Satisfaction of environmental-health needs only prevents people from being dissatisfied; But it does not necessarily cause their motivation and efficiency.

2. In order for people to be aroused, their educational needs must be met. As a result, when people feel satisfied from within, their efficiency and success increase.

3. In order for a person not to be dissatisfied and at the same time to work with high morale and sufficient motivation to achieve great success and efficiency, it is necessary to satisfy both his health and environmental factors and his motivating factors. Also, Robert's 1987 study shows that job-satisfied teachers have a more positive attitude toward students and the teaching profession. A summary of the research shows that the relationship between job satisfaction and organizational commitment and its dimensions has been confirmed in many researches that have been done on different jobs.

The present study with all the above researches (Vahidian Rezazadeh (2002), Azizi (2011), Bazvand, Kashif and Ismaili (2013), Al-Najaz (1996), Yousef (2000), Findler, Wind and Barak (2007), Wood et al. 2007) and Boulogne (1977) in the sense that there is a positive and significant relationship between job satisfaction and organizational commitment.

\section{Conclusion}

Job satisfaction and organizational commitment are the two main factors for the survival and increase of efficiency, effectiveness and productivity of organizations, which force the organization's human resources to achieve the organization with maximum productivity and previously set goals. The Logar state University is a newly established as a public educational institution that plays a role in the education, training and production of science. The present research has been done in this institution.

From the findings of this study, it can be concluded that the majority of the employees of this institution are satisfied with their work; but it is said that their job also requires creativity and initiative. Most of the employees of this institution are not satisfied with the behavior and attitude of the supervisors. On the contrary, the majority of employees read the behavior of colleagues as friendly and satisfied. The majority of the employees of this organization are working in an organization where there is no opportunity for growth and promotion and if so, it is very limited. They have found that promotion is not based on ability and is not enforced in a lawful and orderly manner. Regarding the organizational commitment of the majority of the 
employees of this institution, who is interested in this organization and considers the problems of the organization as its own problems; But the majority say that they do not consider the current organization suitable for them to guarantee their future, and they leave the organization if a better job is offered to them elsewhere.

The results showed that the job satisfaction of the professors and employees of this institution had a great impact on the quality of work in this organization. From the results of this research, it can be cited that the majority of professors and employees of this organization were at a low level of job satisfaction with their supervisors, growth assumptions and payments, and were at a weak or undesirable level of continuous commitment. If they are offered a job elsewhere with high growth opportunities and pay, they find it appropriate to leave the organization. This is while he seems satisfied with the behavior of colleagues and the nature of the job; But they seem completely dissatisfied with the behavior of the supervisors, the opportunities for growth and promotion.

Regarding the research hypotheses, the research results showed that:

There is no relationship between the nature of work and emotional commitment.

There is no significant relationship between the behavior of supervisors and co-workers and value commitment.

There is a significant and positive relationship between growth opportunities and payments and ongoing commitment.

There is a positive and significant relationship between job satisfaction and organizational commitment of the professors and staff of Louvre University.

In summary, it can be said that the first sub-hypothesis (nature of work and emotional commitment) and the second sub-hypothesis (boss-co-worker behavior and normative commitment) are rejected. The third sub-hypothesis (growth opportunities - promotion and ongoing payments and commitment) of the research is confirmed. Also, the main hypothesis (job satisfaction and organizational commitment) of the research is confirmed. In this sense, there is a positive and significant relationship between job satisfaction and organizational commitment of the professors and staff of the Logar state University.

\section{References}

[1] Ashrafi, Bozarg. (1374). Explaining the factors affecting the organizational commitment of managers and employees of East Alborz Coal Company. Master Thesis in Public Management. Knowledge of teacher training.

[2] Azizi, Saeed. (1390). Investigating the Relationship between Job Satisfaction and Organizational Commitment (Case Study of Employees of the General Department of Taxation of Qom Province). Tax Research Journal. PP. 173-196.

[3] Bakhshi and others. ( $\mathrm{I}$ $\mathrm{\Delta}$ ). Organizational commitment and commitment at work. First Edition. Tehran: Qutb Perspective Publications.

[4] Baharifar, Ali Javaheiri and Kamel, Mehdi. (1379). Investigating the Consequences of Organizational Ethical Values by Studying Organizational Justice, Organizational Commitment and Organizational Citizenship Behavior, PP. 118-95.

[5] Bazvand, Kiomers; Kashif, Mir Mohammad and Ismaili, Mohammad Reza. ( 1 rq ). Relationship between emotional intelligence, organizational commitment and job satisfaction of employees of Lorestan General Department of Physical Education. Tehran: Sports Management Publications. Pp. 125-143.

[6] Gholipour, Arian. (2007). Investigating the validity of negative stereotypes of women in organizations. Women's Research. The fifth period. No. 3. Pp. 141-168.

[7] Hersey, Paul and Kent, Blanchard. (1373). Organizational Behavior Management (Human Resource Application). Tehran: Public Management Training Center.

[8] Refin, Ricky and Morehead, Rorry. (1379). organizational behavior. Translated by Seyed Mohammad Alwani and Gholam Reza Memarzadeh. Tehran: Mirvarid Publications. 
[9] Rezaian, Ali. (2004). Fundamentals of Organizational Behavior Management. Tehran: Samat Publications.

[10] Robbins, Stephen \& Jaj, Timothy. (1391). Fundamentals of Organizational Behavior. Translated by Ali Parsaean and Sayed Mohammad Arabi. Sixteenth edition. Tehran: Cultural Research Office Publications.

[11] Shafiabadi, Abdullah. (1997). Professional guidance and advice. Tehran: Roshd Publications.

[12] Kouhestani, Hossein Ali and Shojaeifar, Habibullah. (1380). Relationship between job satisfaction of faculty managers and their organizational commitment in Ferdowsi University of Mashhad. Knowledge and development. Journal of the Faculty of Administrative and Economic Sciences, Froudosi University of Mashhad. PP. 11-26.

[13] Khaki, Ghulam Reza. (1374). Productivity management. Tehran: Islamic Azad University Publications.

[14] Majidi, Abdullah (1998). The Impact of Transfer on Organizational Commitment and Job Satisfaction. Master Thesis in Public Administration. Tehran: Faculty of Humanities.

[15] Maxwell, John. (2008). Scientific-Research Journal of Ofogh-e-Danesh. Fourth edition. Tehran: Danesh Publications.

[16] Moghimi, Seyed Mohammad. (1385). Organization and management (research approach). Tehran: Termeh Publications.

[17] Safiri, Khadijeh. (1998). Sociology of Women's Employment. Tebyan Publications. PP76.

[18] Vahidian, Rezazadeh Majid. (1381). the relationship between job satisfaction and organizational commitment of male physical education teachers. Master Thesis in Physics and Sports Science. Shahid Beheshti University.

[19] Alnajjar, A. A. (1996). Relationship between job satisfaction and organizational commitment among employees in the United Arab Emirates. Psychology Report. PP 315-321.

[20] Wood, J. A., Rutherford, B. Madupalli, R. ,Boles, J. (2007). The relationship of facets of salesperson job satisfaction whit affective organizational commitment. Journal of Business and Industrial Marketing. 22(5): PP 311-321. 